\title{
HOMONIM ANTARA DIALEK MELAYU SARAWAK DAN BAHASA MELANAU
}

\section{THE HOMONYM BETWEEN SARAWAK MALAY DIALECT AND MELANAU LANGUAGE}

\author{
Dayang Sariah Abang Suhai ${ }^{1}$ \\ Mary Fatimah Haji Subet ${ }^{2}$ \\ Centre for Language Studies, Universiti Malaysia Sarawak \\ 1asdsariah@cls.unimas.my ${ }^{2}$ sufatimah@cls.unimas.my
}

\begin{abstract}
Abstrak
Homonim merupakan suatu aspek yang terkandung dalam sistem makna. Bentuk homonim ini bukan sahaja wujud dalam satu bahasa masyarakat yang sama, tetapi turut dijumpai dalam beberapa bahasa yang berlainan latar belakang penuturnya. Oleh itu, makalah ini akan memfokus kepada bentuk istilah yang sama ejaan dan sama sebutannya dalam dialek Melayu Sarawak (DMS) dengan bahasa Melanau. Data-data yang dibincangkan dalam makalah ini diambil daripada data yang telah didokumenkan. dan juga berdasarkan data yang dikumpul oleh penulis melalui catatan lapangan. Sumber data sekunder yang digunakan ialah Kamus Melanau Mukah - Melayu Dewan (2011) dan Daftar Kata Dialek Melayu Sarawak Edisi Kedua (1998). Penelitian ini mendapati bahawa terdapat kosa kata yang sama ejaan dan sama sebutan dalam bahasa Melanau sememangnya mempunyai persamaan dan juga perbezaan makna dalam DMS.
\end{abstract}

Kata kunci: homonim, Dialek Melayu Sarawak, bahasa Melanau

\begin{abstract}
Homonym is an aspect in the meaning system. Homonymous form does not only exist within the same language society, but is also found in several different language societies with different background of speakers. Therefore, this paper will focus on the same terms of the same spellings and pronunciations as spoken in the Sarawak Malay dialect (DMS) and Melanau language. The data discussed in this paper are taken from documented data which are based on the data collected by the author via observation. Secondary data sources used are Kamus Melanau Mukah - Melayu Dewan (2011) dan Daftar Kata Dialek Melayu Sarawak Edisi Kedua (1998). This research found that there are vocabularies in the Melanau language which are similar in spellings and pronunciations with Sarawak Malay Dialects but are different in terms of meanings.
\end{abstract}

Keywords: homonym, Sarawak Malay dialect, Melanau language 


\section{Pendahuluan}

Apabila seseorang penutur yang sememangnya kita ketahui sedang bertutur dalam bahasa atau dialeknya, namun dalam masa yang sama menyebut beberapa leksikal yang sama sebutan dengan bahasa atau dialek kita, pasti kita cuba mencari atau memahami akan maksud yang dilambangkan oleh leksikal yang diungkapkannya itu. Tanggapan awal kita pasti akan membandingkan sama ada leksikal yang diujarkan itu mempunyai maksud yang sama dalam bahasa atau dialek seharian kita ataupun sememangnya mempunyai makna yang berbeza. Hal ini pernah dinyatakan oleh Noriah Mohamed dan Rohani Mohd. Yusof (2004, p. 281), iaitu penutur natif bahasa Melayu yang pernah mendengar orang Iban bertutur akan mengenal pasti sesetengah kosa kata bahasa Iban kelihatan atau berbunyi lebih kurang sama dengan kosa kata dalam bahasa Melayu. Misalnya kosa kata besar, makan dan panjang dalam bahasa Melayu masing-masing akan menjadi 'besai', 'makai' dan 'panjai' dalam bahasa Iban yang juga membawa makna yang sama. Menurut Noriah Mohamed dan Rohani Mohd. Yusof (2004, p. 282), unsur-unsur yang sama atau mirip dari segi bentuk dan makna ini disebut unsur berkognat, iaitu berada dalam bahasa bersanak yang wujud disebabkan unsur berkenaan berasal daripada bahasa induk yang sama. Berdasarkan kajian tersebut, Noriah Mohamed dan Rohani Mohd. Yusof (2004) mendapati antara 10 bahasa Austronesia yang dituturkan di Sarawak mempunyai hubungan sanak yang masih dekat dan terdapat juga hubungan yang sudah agak jauh. Misalnya bahasa Melayu mempunyai hubungan sanak taraf keluarga dengan bahasa Selakau, Iban, Bintulu, Melanau, Miriek, Bidayuh, Lunbawang, dan Kiput, namun mempunyai hubungan rumpun dengan bahasa Bukit.

Rentetan kajian Noriah Mohamed dan Rohani Mohd. Yusof (2004) ini, wujud persoalan, adakah semua kosa kata yang sama atau mirip bentuk ejaan atau sebutannya itu mewakili makna yang sama dalam dua atau lebih daripada dua dialek atau bahasa yang dibandingkan? Jika disoroti kajian yang dilakukan oleh Abdul Hamid Mahmood (2006) dan Mary Fatimah Subet, Dayang Sariah Abang Suhai, Nur Ardini Jian Abdullah dan Salbia Hassan (2011), terdapat perbezaan dapatan daripada hasil kajian Noriah Mohamed dan Rohani Mohd. Yusof (2004). Kedua-dua pengkaji ini membandingkan kosa kata dasar dalam bahasa Melayu standard (BMS) yang sama sebutan dan sama ejaannya dengan dialek-dialek Melayu yang lain. Walau bagaimanapun, dapatan mereka menunjukkan bahawa terdapat perbezaan makna yang ketara bagi kosa kata yang dibandingkan. Misalnya kajian Abdul Hamid Mahmood (2006) yang menyenaraikan beberapa kosa kata yang sama sebutan dan sama ejaannya dalam BMS, jelas mempunyai makna yang berbeza dalam dialek Melayu Kelantan (DMK). Contohnya kosa kata rajin yang bermaksud 'tekun' dalam BMS, berbeza maknanya dalam DMK, iaitu 'pernah', begitu juga dengan kosa kata selalu (BMS - 'kerap'; DMK 'segera'), dan sisa (BMS - 'buangan, apa-apa yang tertinggal sesudah dimakan, dipakai atau sebagainya'; DMK - 'sagu hati untuk tetamu majlis perkahwinan'). Sementara itu, kajian Mary Fatimah Subet et al. (2011) membandingkan beberapa kosa kata yang sama dalam BMS dengan dialek Melayu Sarawak (DMS). Kajian Mary Fatimah Subet et al. (2011) turut membuktikan bahawa kosa kata yang sama ejaan dan sebutan tersebut mempunyai makna yang berbeza dalam DMS, contohnya kosa kata kepak (BMS - 'sayap'; DMS - 'penat'), kelakar (BMS - 'jenaka'; DMS - 'bercakap') dan tikam (BMS - 'menikam dengan pisau dan sebagainya'; DMS - 'melontar sesuatu'). Hal ini menunjukkan bahawa leksikal yang sama sebutan dan ejaannya dalam sesuatu bahasa boleh membentuk banyak makna.

Dalam bidang linguistik, perkataan yang sama bunyi atau sama ejaannya dengan perkataan lain tetapi berbeza maknanya disebut sebagai homonim (Kamus Dewan, 2007, p. 544). Abdullah Hassan pernah menyebut bahawa kata-kata homonim biasanya dianggap 
sebagai dua kata yang berasingan dan diberi dua kata masukan dalam kamus (Siti Saniah Abu Bakar, Che Ibrahim Salleh, Arba'ie Sujud \& Ahmad Mahmood Musanif, 2009, p. 534). Oleh sebab itu, kamus-kamus bahasa yang diterbitkan akan memasukkan bentuk kata yang homonim ini sebagai entri yang berasingan dan dilambangkan dengan angka-angka I, II, III atau seterusnya. Misalnya perkataan banci dalam Kamus Dewan (2007, p. 119), dimasukkan sebagai tiga entri, iaitu I perhitungan (bilangan penduduk, lalu lintas, dII); II bersifat lelaki dan perempuan, tidak lelaki dan tidak perempuan; dan banci III sejenis perkakas pertukangan kayu.

\section{Latar Belakang}

Rentetan daripada kajian Noriah Mohamed dan Rohani Mohd. Yusof (2004), kajian ini pula hanya akan membandingkan dua bahasa yang dituturkan di Sarawak, iaitu dialek Melayu Sarawak (DMS) dan bahasa Melanau (BMel). Kajian Noriah Mohamed dan Rohani Mohd. Yusof (2004) telah menggunakan 100 kosa kata dasar yang pernah digunakan oleh Morris (1971) untuk menentukan peratusan kata yang berkognat. Namun, kajian ini akan menggunakan sumber data yang telah didokumenkan dan juga berdasarkan data yang dikumpul oleh penulis melalui catatan lapangan. Sumber data sekunder yang dijadikan perbandingan ialah kosa kata yang terdapat dalam Kamus Melanau Mukah - Melayu Dewan (2011) dan Daftar Kata Dialek Melayu Sarawak Edisi Kedua (1998).

Mengapa DMS dan BMel dijadikan perbandingan? Berdasarkan catatan kajian terdahulu, kedua-dua kumpulan penuturnya iaitu masyarakat Melayu dan Melanau sering dikaitkan dengan latar belakang identiti budaya yang hampir sama. Morris (1971) pernah menyatakan bahawa sesetengah individu dalam komuniti Melanau itu sendiri terkeliru akan identiti mereka sama ada 'Melayu' atau 'Melanau'. Namun menurut beliau, perkataan 'Melayu' yang digunakan dalam BMel sebenarnya bermaksud seseorang yang memeluk Islam dan bukannya mewakili kumpulan etnik Melayu. Jamuh (1973) turut menggelar golongan Melanau yang telah memeluk Islam sebagai 'Mohammedan' dan 'masuk Melayu'. Sebenarnya hubungan Melanau - Melayu ini wujud sejak masyarakat Melanau ditakluk oleh Kesultanan Brunei pertengahan abad ke-15 dan seterusnya kemasukan pedagang dan pentadbir Melayu dalam zaman Brooke serta kesan perkahwinan campur antara Melanau dengan Melayu, menyebabkan agama Islam lebih luas pengaruhnya dan telah lama terdedah dalam komuniti Melanau (Yasir Abdul Rahman, 1987). Oleh sebab itu, ada pihak yang berpendapat bahawa orang Melanau ini sukar dibezakan daripada masyarakat Melayu.

Di samping itu, hasil kajian Noriah Mohamed dan Rohani Mohd. Yusof (2004) mendapati bahawa BMel mempunyai hubungan persanakan atau kekeluargaan dengan bahasa Melayu. Hal ini dibuktikan melalui peratusan kosa kata BMel yang berkognat dengan bahasa Melayu mencapai 50 peratus, iaitu berada dalam tingkat keluarga. Kemiripan bentuk dan kesamaan makna bagi kosa kata tersebut dibuktikan melalui perbandingan kosa kata seperti "semua = semuah", "abu = abo", "darah = darak", "mati = matai", "awan = awan", dan "telinga = lingah" ${ }^{\prime \prime}$. Berdasarkan perbandingan kosa kata tersebut, BMel dilihat seakanakan menyerupai bahasa Melayu ataupun lebih mudah difahami kerana kemiripan bentuk kosa katanya turut membawa makna yang sama dalam bahasa Melayu. Oleh itu, tidak mustahil seseorang pendengar yang bukan penutur BMel akan menganggap bahawa BMel itu adalah lebih mudah difahami kerana tidak jauh bezanya dengan kosa kata bahasa Melayu. Walau bagaimanapun, kajian Noriah Mohamed dan Rohani Mohd. Yusof (2004) ini

\footnotetext{
${ }^{1}$ Kosa kata yang dicetak italik mewakili bahasa Melanau.
} 
turut memberi sumbangan bermakna dalam kajian Linguistik Sejarah dan Perbandingan kerana berjaya mengelompokkan 10 bahasa Austronesia yang terdapat di Sarawak berdasarkan ciri-ciri linguistik kosa kata tersebut dan seterusnya menentukan hubungan persanakan bahasa-bahasa berkenaan.

Rentetan daripada kajian Noriah Mohamed dan Rohani Mohd. Yusof (2004), kajian ini hanya akan memfokus kepada perbandingan kosa kata dalam DMS dengan BMel. Bagi pengkaji, DMS dijadikan perbandingan kerana dialek Melayu ini yang dituturkan di Sarawak dan bukannya bahasa Melayu standard (BMS) seperti yang dibandingkan oleh Noriah Mohamed dan Rohani Mohd. Yusof (2004). Selain itu, kebanyakan penutur BMel boleh bertutur dalam DMS sebagai bahasa perantara dengan penutur Melayu yang tidak tahu berbahasa Melanau. Oleh itu, perbandingan BMel dengan DMS dianggap lebih relevan kerana kedua-dua bahasa dan dialek ini wujud dalam konteks bahasa yang dituturkan di Sarawak.

\section{Dapatan dan Perbincangan}

Kajian ini dilakukan dengan mengenal pasti dan mengumpulkan kosa kata yang sama ejaan dan sama sebutan dalam DMS dan BMel. Sumber data sekunder yang digunakan ialah Kamus Melanau Mukah - Melayu Dewan (2011) dan Daftar Kata Dialek Melayu Sarawak Edisi Kedua (1998). Berdasarkan kosa kata yang dikumpul, makna kosa kata dapat dikenal pasti sama ada mempunyai hubungan kognat ataupun lebih bersifat homonim.

Jadual 1 di bawah menunjukkan senarai kosa kata yang telah dikumpul secara rambang, iaitu tidak melibatkan keseluruhan kosa kata yang terdapat dalam kedua-dua dokumen tersebut. Hal ini demikian kerana fokus kajian ini adalah untuk mengenal pasti sama ada wujudnya makna yang sama atau berbeza bagi kosa kata yang sama dalam keduadua bahasa dan dialek yang dibandingkan, dan bukannya melibatkan kajian leksikostatistik atau kaedah perbandingan kosa kata dasar yang melibatkan peratusan.

Berdasarkan jadual di atas, didapati kosa kata dalam DMS dan BMel mempunyai unsur kesamaan bentuk dan kemiripan cara penyebutan, namun makna yang dimaksudkan ada yang sama (kognat) dan juga berbeza (homonim). Contoh kosa kata yang berkognat ialah ayan dan agak. Kosa kata ayan membawa maksud 'dedah' dan agak bermaksud 'agak' dalam DMS dan BMel. Namun dalam BMel, kosa kata ayan dan agak ini mempunyai dua entri yang berhomonim, iaitu dengan makna yang berlainan. Bentuk homonim bagi entri ayan ialah I 'lapan' dan II 'dedah', manakala entri agak dilambangkan dengan homonim I 'keranda, peti mayat' dan II 'agak'. Meskipun kosa kata ayan dan agak mempunyai hubungan kognat antara DMS dan BMel, namun kesamaan makna tersebut bukan merujuk makna utama dalam BMel. Kesamaan maknanya dalam BMel hanya wujud dalam entri hominim kedua, sedangkan makna utama kosa kata tersebut ditunjukkan dalam entri homonim I.

Di samping itu, perbezaan makna yang homonim antara DMS dan BMel jelas ditunjukkan bagi kebanyakan kosa kata seperti manok, pisang, lupit, madam, sak, adik, dan manek. Kosa kata manok bermaksud 'ayam' dalam DMS, tetapi 'burung' dalam BMel, begitu juga dengan pisang (DMS - 'buah pisang'; BMel - 'buah nanas'), sak (DMS - 'perasaan sakit hati'; BMel - 'warna merah'), dan lengan (DMS - 'bahagian badan dari bahu hingga ke pergelangan tangan'; BMel - 'suara'). 
Jadual 1

Perbandingan Makna Kosa Kata dalam Dialek Melayu Sarawak - Bahasa Melanau

\begin{tabular}{|c|c|c|}
\hline Kosa kata & $\begin{array}{c}\text { Makna dalam Dialek Melayu } \\
\text { Sarawak }\end{array}$ & Makna dalam Bahasa Melanau \\
\hline Pisang [pisaN] & (kn) buah pisang & (kn) buah nanas \\
\hline Manok [mano?] & $(\mathrm{kn})$ ayam & (kn) burung \\
\hline \multirow[t]{2}{*}{ Ayan [ajan] } & (kk) dedah & I (kn bilangan) lapan \\
\hline & & II (kk) dedah \\
\hline Sak [sak] & (ka) perasaan sakit hati & (kn) warna merah \\
\hline Padam [padam] & (kk) tutup / matikan suis & (ka) keadaan sekeliling yang gelap \\
\hline Abi [abi] & (kn) bekas luka, kudis & $\begin{array}{l}\text { (kn) takuk, takik pada bahagian } \\
\text { pokok yang ditebang, bekas } \\
\text { torehan }\end{array}$ \\
\hline Adek [ade?] & $\begin{array}{l}\text { (kt seruan) keluhan yang } \\
\text { menunjukkan rasa sakit, aduh }\end{array}$ & (ka) pendek \\
\hline Adik [adi?] & $\begin{array}{l}\text { (kn) saudara kandung (lelaki atau } \\
\text { perempuan) yang lebih muda. }\end{array}$ & \\
\hline Angat [aNat] & (ka) panas & (kk) usik \\
\hline \multirow[t]{2}{*}{ Asak [asa?] } & (ka) suka & I (kn) itik serati, itik nila \\
\hline & & II (kk) asah \\
\hline Asap [asap] & $\begin{array}{l}\text { (kn) gas yang kelihatan keluar dari } \\
\text { benda yang dibakar (berkepul- } \\
\text { kepul naik ke udara) }\end{array}$ & $\begin{array}{l}(\mathrm{kn}) \text { sj udang kecil air tawar yang } \\
\text { warnanya dapat berubah-ubah } \\
\text { menurut habitatnya }\end{array}$ \\
\hline \multirow[t]{2}{*}{ Agak [aga?] } & (kk) agak & I (kn) keranda, peti mayat \\
\hline & & II (kk) agak \\
\hline lengan [leNan] & $\begin{array}{l}(\mathrm{kn}) \text { bahagian badan dari bahu } \\
\text { hingga ke pergelangan tangan }\end{array}$ & (kn) suara \\
\hline Susut [susut] & (ka) mengecil & (kk) mengekori, turut serta \\
\hline $\begin{array}{l}\text { Nyabong [ JaboN] } \\
\text { Nyabuong [Jabu } \Omega \text { [n] }\end{array}$ & (kk)perbuatan melagakan & $\begin{array}{l}\text { I (kn) haluan, bahagian depan } \\
\text { perahu, kapal, dll. }\end{array}$ \\
\hline Nyabuong [ Jabu $\Omega \square$ ] ] & & II (kn) pokok raba \\
\hline \multirow[t]{2}{*}{ Lupit [lupit] } & $(\mathrm{kn})$ hari selepas lusa & $\begin{array}{l}\text { I (kn) sj ikan laut yang kulitnya } \\
\text { mudah disiat }\end{array}$ \\
\hline & & II (ka) luka yang ringan \\
\hline \multirow[t]{2}{*}{ Madam [madam] } & (kk) memadamkan & I (ka) busuk (bau), busuk hati \\
\hline & & II (ka) dungu, bebal, bodoh \\
\hline Manek [mane?] & (kn) petanda, tanda-tanda & (kk) berak \\
\hline
\end{tabular}


Perbezaan makna dalam kedua-dua bahasa dan dialek tersebut turut menunjukkan bahawa kategori kelas kata bagi senarai kosa kata yang dikenal pasti ada yang sama dan berubah. Kategori kelas kata yang sama ialah KN (kata nama) - KN, dan KK (kata kerja) - KK dalam DMS dan BMel. Contoh kosa kata KN - KN ialah pisang, manok, abi, asap, lengan, dan lupit. Manakala contoh kosa kata yang wujud dalam kategori KK - KK ialah ayan dan agak. Meskipun kelas kata kosa kata ini sama dalam DMS dan BMel, namun maknanya ada yang sama dan lebih banyak yang berbeza.

Selain itu, kelas kata yang berbeza juga wujud apabila makna yang diwakili kosa kata yang sama tersebut berbeza maknanya antara DMS dan BMel. Terdapat bentuk KN - KA (kata adjektif), KA - KN, KK - KA, KA - KK, KN - KK, KK - KN. Contoh kosa kata KN - KA ialah adik [DMS (KN) - 'saudara kandung (lelaki atau perempuan) yang lebih muda'; BMel (KA) 'pendek'] dan lupit [DMS (KN) - 'hari selepas lusa'; BMel (KA) - 'luka yang ringan'], manakala bentuk KA - KN pula ialah kosa kata sak [DMS (KA) - 'perasaan sakit hati'; BMel (KN) 'warna merah']. Contoh kosa kata kategori KK - KA ialah padam [DMS (KK) - 'tutup, matikan suis'; BMel (KA) - 'keadaan sekeliling yang gelap'] dan madam [DMS (KK) - 'memadamkan'; BMel (KA) - I 'busuk (bau), busuk hati', II 'dungu, bebal, bodoh']. Bagi kategori KA - KK pula ialah angat [DMS (KA) - 'panas'; BMel (KK) - 'usik'], asak [DMS (KA) - 'suka'; BMel (KK) 'asah'] dan susut [DMS (KA) - 'mengecil'; BMel (KK) - 'mengekori, turut serta']. Kategori KN KK diwakili oleh kosa kata manek [DMS (KN) - 'petanda, tanda-tanda'; BMel (KK) - 'berak'], dan kategori sebaliknya, iaitu KK - KN ialah kosa kata nyabong [DMS (KK) - 'perbuatan melagakan'; BMel (KN) - 'haluan, bahagian depan (perahu, kapal)'].

Berdasarkan kajian ringkas ini, didapati BMel dan DMS mempunyai persamaan dari segi kosa kata yang digunakan dalam pertuturan seharian. Persamaan tersebut dapat dilihat melalui kosa katanya yang sama sebutan dan sama ejaannya, contohnya manok, pisang, ayan, sak, dan padam. Namun demikian, persamaan atau kemiripan bentuk ini tidak bermaksud bahawa kedua-dua bahasa dan dialek ini berkongsi makna yang sama, sedangkan kebanyakan makna kosa kata tersebut tetap berbeza. Hal ini membuktikan bahawa bentuk hubungan yang berlaku antara DMS dan BMel ialah bersifat homonim. Bentuk homonim bukan sahaja berlaku dalam satu bahasa dengan dialek-dialeknya, tetapi boleh melibatkan satu bahasa dengan bahasa yang lain, atau satu bahasa dengan dialek dalam bahasa yang lain.

\section{Kesimpulan}

Persamaan kosa kata tetapi wujud perbezaan makna bukan sahaja wujud dalam bahasa atau dialek yang sama, tetapi turut berlaku antara satu bahasa dengan bahasa yang lain, ataupun antara suatu dialek dengan bahasa yang lain. Kosa kata yang berhomonim antara dialek Melayu Sarawak dan bahasa Melanau membuktikan bahawa kedua-dua kumpulan penutur suku kaum ini sebenarnya terdiri daripada lingkungan komuniti yang tersendiri. Sekiranya berlaku komunikasi antara penutur yang berlainan suku kaum ini, pasti akan berlaku salah faham terhadap makna yang dimaksudkan oleh kosa kata yang sama digunakan kerana tidak memahami atau mempelajari bahasa antara satu sama lain. Keadaan ini secara tidak langsung boleh menyebabkan berlakunya komunikasi yang kurang berjaya. Justeru, kelainan makna bagi kosa kata yang sama dalam bahasa-bahasa ini perlu diketahui untuk mewujudkan persefahaman dan mengelakkan masalah dalam komunikasi.

\section{Rujukan}

Abdul Hamid Mahmood. (2006). Sintaksis dialek Kelantan. Kuala Lumpur: Dewan Bahasa dan Pustaka. 
Jamuh, G. (1973). Some Melanau customs and taboos. Sarawak Museum Journal.

Kamus Dewan Edisi Keempat. (2007). Kuala Lumpur: Dewan Bahasa dan Pustaka.

Kamus Melanau Mukah - Melayu Dewan. (2011). Kuala Lumpur: Dewan Bahasa dan Pustaka.

Mary Fatimah Subet, Dayang Sariah Abang Suhai, Nur Ardini Jian Abdullah, \& Salbia Hassan. (2011). Dialek Melayu Sarawak: Kelainan semantik. MANU, 17, 131- 145.

Morris, H. S. (1971). Report on a Melanau sago producing community in Sarawak. London: Johnson Reprint Corporation.

Noriah Mohamed, \& Rohani Mohd. Yusof. (2004). Persamaan dan kemiripan bahasa: Perbandingan kosa kata dasar 10 bahasa Austronesia di Sarawak. Jurnal Bahasa, $4(2), 278-359$.

Siti Saniah Abu Bakar, Che Ibrahim Salleh, Arba'ie Sujud, \& Ahmad Mahmood Musanif. (2009). Retorik homonim dalam korpus iklan. Prosiding Seminar Linguistik dan Pembudayaan Bahasa Melayu V, 534-540.

Yasir Abdul Rahman. (1987). Melanau Mukah: satu kajian budaya. Kuala Lumpur: Dewan Bahasa dan Pusta. 